\title{
Results of the combined use of Ozone and PRP with a novel skin rejuvenation system called the OxyPin [abstract]
}

\author{
Julian Holmes \\ Chelsea Aesthetic Clinic, Waterloo Road, Wynberg, Cape Town, Western Province. Republic of South Africa
}

\section{ABSTRACT}

\section{OPEN ACCESS}

\section{Citation}

Holmes J. Results of the combined use of Ozone and PRP with a novel skin rejuvenation system called the OxyPin [abstract]. Proceedings of The World Conference on Ozone Therapy in Medicine, Dentistry and Veterinary. Ancona (Italy). September 22nd - 23rd - 24th, 2017. J Ozone Ther. 2019;3(4):27. doi: 10.7203/ jo3t.3.4.2019.15508

\section{Academic Editor \\ Jose Baeza-Noci, \\ School of Medicine, Valencia University,} SPAIN

\section{Editor}

World Federation of Ozone Therapy, Bolgna, ITALY

\section{Received}

June 17, 2019

\section{Accepted}

December 08, 2019

\section{Published}

December 30, 2019

\section{Intellectual Property}

Julian Holmes.

This is an open access article distributed under the terms of the Creative Commons Attribution License (CC BY 4.0), which permits unrestricted use, distribution, and reproduction in any medium, provided the original author and source are credited.

\section{Author Information}

drjulianholmes@gmail.com
Introduction: Facial Aesthetics enjoys a huge commercial market in every country around the world. To date, chemical peels, laser treatment, the dermal roller and so on have all had a part to play in skin renewal and the quest for a younger looking face and body. Both Ozone and PRP have a role to play in tissue rejuvenation and repair, and when used in conjunction with fillers, new exciting possibilities open to the clinician.

Dr Holmes will showcase a new technology known as The OxyPin where ozone and PRP or other serums can be combined into a simple, predictable treatment protocol with great results. Dr Holmes will discuss the conversion kit required, and show before and after cases to illustrate this simple technique that can be mastered by any clinician.

Purpose. The purpose of this research was to show the synergistic effects of PRP, ozone and a new skin treatment device called The OxyPin.

Methods: Clients were asked to take part in either conventional needling or use of the new OxyPin device.

Conclusions: The ease of use and low learning curve with this technology makes it accessible for a wide range of therapists in the beauty industry. The OxyPin device is easy to set up, use and clean. The combination of PRP and ozone therapy with the OxyPin, has resulted in outstanding results. 